\title{
TIPOLOGÍA TEXTUAL Y TEXTO LITERARIO
}

\author{
Rafael NÚÑEZ RAMOS \\ Universidad de Oviedo
}

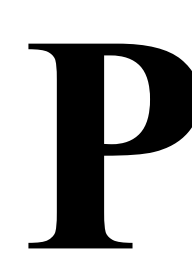

\section{rincipios generales}

Las teorías del texto lo definen en sus aspectos más generales: la unidad, la coherencia, la articulación interna, la informatividad, la pertinencia comunicativa; es decir, lo que todos los textos comparten ${ }^{1}$. Esta caracterización permite comprenderlos y manejarlos de manera intuitiva, ágil e incluso eficaz, pero sin una conciencia clara de los mecanismos más profundos que actúan sobre el lector. Los textos concretos, por su parte, son muy diferentes unos de otros y no exhiben claramente su mecanismo textual. No existen indicadores formales que permitan identificar claramente partes y o funciones del texto, como las categorías morfológicas y las sintácticas lo hacen con la palabra y la oración. Por esto mismo y porque contenidos funcionalmente diversos pueden superponerse o permanecer implícitos, su organización interna no responde a esquemas que tengan una expresión formal y puedan ser reconocidos de manera inmediata en el acto de lectura.

Resulta, pues, muy complicado, articular un modelo formal de texto que se pueda proyectar satisfactoriamente sobre la superficie de cualquier texto concreto para clarificar los mecanismos que le permiten cumplir su función, esto es, realizar las intenciones del autor y conseguir la comprensión y respuesta del lector. No existe un sistema de organización de los enunciados que pueda aplicarse a todos los textos como unidades de significación e interacción comunicativa. Sin embargo, la gran heterogeneidad de los textos concretos se reduce cuando se distribuyen en unos cuantos tipos y se reconocen sus peculiaridades y diferencias a partir de principios estables y homogéneos.

Nuestro propósito es estudiar los principios de organización de los textos para intentar comprender las pautas de variación, las fronteras entre los diversos tipos y los criterios de adscripción a uno específico. Las cuestiones relacionadas con el concepto de texto en general serán tratadas de manera colateral y, en cuanto a las cuestiones que tienen que ver con la tipología, nuestro propósito no es profundizar en sus bases teóricas, ni proponer una nueva, ni hacer una caracterización exhaustiva de los diferentes tipos, sino, como queda dicho, analizar cómo los textos concretos pueden adscribirse a un único tipo, a pesar de las ambigüedades, las semejanzas y las confluencias que pueda haber entre

\footnotetext{
${ }^{1}$ Creemos que la obra de Beaugrande y Dressler (1981) sigue constituyendo una visión clara y exhaustiva de estas cuestiones.
} 
ellos. Nos ocuparemos más de los problemas que puedan plantearse para clasificar un texto dentro de la tipología que de la tipología en sí misma.

Desde hace mucho tiempo la mayor parte de las propuestas de tipos de texto derivan de la presentada por Werlich (1975), que comprende cinco categorías: descriptivo, expositivo, regulativo, narrativo y argumentativo. Ha sido reproducida, con variantes, por muchos autores y, en lo sustancial, ha alcanzado un consenso bastante amplio. Por ello no resulta fácil reemplazarla con tanta unanimidad. Tampoco lo creemos necesario, pues nos parece una clasificación homogénea, exhaustiva y operativa. Sí nos parece conveniente, para nuestro propósito, modificar lo que Isenberg llama «base de tipologización», en busca de una mayor transparencia de las relaciones entre los tipos, de principios claros para explicar las múltiples variaciones y resolver ambigüedades y, finalmente, de un criterio para ubicar a los textos literarios dentro del cuadro general.

La base que proponemos está formada por tres factores y los tipos de texto se definen por su comportamiento en relación con ellos conjuntamente ${ }^{2}$.

El primer factor es el carácter de la información, que puede ser concreta si se refiere a entidades, hechos, circunstancias, propiedades individuales: el puente de Rande, el hundimiento de un barco, el rostro del presidente; o abstracta, si se refiere a conceptos, ideas, generalizaciones: la costumbre de la siesta, la libertad, la fabricación de salchichas, la eficacia de los antibióticos.

El segundo factor es la organización, que puede ser paratáctica, cuando la información se acumula sin conexiones profundas más allá de la mera concurrencia en el texto y en su dominio referencial: «La casa tenía dos plantas y un sótano, en la planta baja había una cocina, una sala...»; «Juan había nacido en Figueras, era arquitecto, le gustaba el fútbol, tenía tres hijos»; o hipotáctica cuando existe una articulación fuerte, de tipo lógico o causal, entre los contenidos referidos por el texto: «Se fue de casa porque quería tener autonomía»; «También los jóvenes tienen que enseñar a los mayores, ya que captan más fácilmente las novedades que hay que dominar, por tener su sensibilidad más abierta y menos sometida a la rutina».

Por último, la orientación puede ser informativa, si el texto reúne información para hacérsela saber al lector con el objetivo de que este la conozca, o apelativa, cuando pretende que el lector, al participar en el proceso de articulación de los contenidos, asuma una parte específica de estos.

Antes de trazar un perfil independiente de cada uno de los tipos y teniendo en cuenta que nuestro objetivo se centra en las relaciones entre ellos, repasaremos su posición con respecto a los factores que los definen.

\section{Tipos de texto y factores de clasificación}

Si proyectamos los tres factores sobre los tipos de texto, podemos establecer las siguientes oposiciones entre ellos.

\footnotetext{
${ }^{2}$ Concebimos estos factores como un desarrollo de las condiciones que definen al texto como unidad de interacción comunicativa; aunque somos nosotros quienes proponemos la interrelación entre ellas y su definición última, nos apoyamos en ideas de Kibedi-Varga, A. (1989).
} 


\section{Contenido concreto frente a contenido abstracto}

Según esta categoría, los textos descriptivos y narrativos se oponen a los textos expositivos y argumentativos $^{3}$. Los primeros se circunscriben al dominio de lo concreto; los segundos, sin rechazar lo concreto, se organizan en torno a abstracciones.

En efecto, el texto narrativo y el texto descriptivo se refieren a datos concretos, a objetos, hechos y relaciones en su individualidad, mientras que el texto expositivo y el texto argumentativo integran lo concreto en generalizaciones, interpretaciones, abstracciones en suma. En un texto descriptivo las frases dominantes son del tipo: «La bolsa de basura era negra, estaba mal cerrada y dejaba asomar un zapato viejo, unos restos de lechuga y un paraguas roto», es decir, se refiere a un objeto único, una bolsa de basura concreta y única, que se reconoce como tal por concurrir en ella una serie de rasgos; en un texto narrativo las frases se refieren también a algo concreto, en este caso acciones o acontecimientos: «Germán salió corriendo y dejó la bolsa de basura en el contenedor». Por el contrario, en los textos expositivos y argumentativos, aunque pueden aparecer enunciados sobre objetos o hechos concretos y únicos, los dominantes son del tipo: «La basura refleja la intimidad de las personas»o «Las bibliotecas personales son un anacronismo», es decir, tratan de ideas, abstracciones, agrupaciones de entidades individuales consideradas en lo que tienen de común: la basura o las bolsas de basura en general.

Hay que tener en cuenta que lo abstracto es una elaboración a partir de lo concreto y lo incluye; los textos expositivos y argumentativos, que tienen una indudable orientación hacia lo abstracto, incorporan con naturalidad referencias a todo tipo de entidades concretas, que, en cualquier caso, quedan aludidas, en sus aspectos esenciales, en las abstracciones:

Cenando de madrugada en una fonda con un grupo de obreros me doy cuenta de que lo que separa los que se llama las clases sociales no son tanto las ideas como los modales. Probablemente, yo compartía las aspiraciones de mis comensales y, más aún, estaba mejor preparado que ellos para defenderlas; pero lo que nos alejaba irremediablemente era la manera de coger el tenedor.

Como se ve, el texto comienza con una alusión a un hecho concreto, la cena del autor con los obreros, del que inmediatamente se pasa a un pensamiento abstracto: lo que separa a las clases sociales son más los modales que las ideas. La argumentación, de hecho, es un recorrido de las ideas a los hechos, de los hechos a las ideas y de las ideas a otras ideas, tiene que superar lo concreto, pero no es necesario que lo elimine, de hecho las abstracciones lo llevan incorporado de manera simplificada y se basan, precisamente, en su capacidad de integrarlo, de manera que las referencias directas o hechos $\mathrm{u}$ entidades específicas son totalmente naturales. Por esto mismo, el texto expositivo, que se refiere a entidades abstractas, las incorpora sin violencia alguna; véanse, por ejemplo, los siguientes párrafos, extraídos de un texto expositivo sobre el bostezo que recoge la experiencia particular de un individuo en un momento concreto:

\footnotetext{
${ }^{3}$ Por razones prácticas, dejamos de lado los textos regulativos cuya consideración no aportaría gran cosa a nuestros propósitos y, sin embargo, exigiría abundante espacio.
} 


\begin{abstract}
Desde el punto de vista psíquico y funcional, en 1986 el psicólogo estadounidense Robert Provine considera al bostezo en el humano como el mejor ejemplo de un acto motor estereotipado, que puede iniciarse por una variedad de estímulos, en particular por la observación de una persona bostezando, circunstancia que lo hace contagioso. También señala que se desencadena por estados de fatiga o aburrimiento.

[...] Tal parece que del bostezo no se escapan ni los políticos. En una parte de su libro de memorias, el expresidente José López Portillo narra las reacciones internas que tuvo en el momento de enterarse que sería el futuro primer mandatario de México. Recuerda que su primera sensación fueron las ganas intensas de bostezar, que logró contener realizando un esfuerzo para no hacerlo en tan crucial momento.
\end{abstract}

\title{
Parataxis frente a hipotaxis
}

Si atendemos a la organización del contenido, a las relaciones entre los enunciados o entre las partes de los textos, los tipos de texto se distribuyen de otra forma. Por un lado, el texto descriptivo y el texto expositivo acumulan la información, reúnen los datos y las ideas sobre una entidad o un tema, sin preocuparse por conectarlas en un entramado lógico. El principio de crecimiento del texto es la parataxis, la yuxtaposición de enunciados relativos al objeto. El texto descriptivo yuxtapone los contenidos acerca de una entidad particular: «La bolsa de basura era negra, contenía un zapato, trozos de un plato roto, el recibo de la comunidad, y otras cosas que no se podían identificar; estaba reventada por un lado...».

El texto expositivo hace lo propio con una entidad abstracta, es decir, reúne enunciados sin necesidad de establecer enlaces fuertes entre ellos, únicamente los que se refieren a la coexistencia en el domino abstracto de que se trate: «El cómic, también llamado historieta o tebeo, es un relato narrativo ilustrado, cuya acción se sucede en diversas viñetas. Podríamos considerar el cómic como un medio especial de comunicación de masas cuya finalidad es el entretenimiento de los lectores».

El texto narrativo y el argumentativo, por el contrario, se identifican por proponer relaciones lógicas entre sus contenidos (hipotaxis). El texto narrativo, entre las acciones, sus motivaciones y sus consecuencias: «La policía registró la bolsa de basura para encontrar pruebas que incriminaran al sospechoso».

El texto argumentativo, entre las ideas y los datos para obtener nuevas ideas: «La intimidad es un bien jurídico que merece protección, puesto que la basura contiene rastros de la intimidad de las personas, por tanto la basura debe acogerse a la protección de la intimidad».

No faltan en los textos descriptivos y expositivos los elementos de relación, pero, o bien no expresan una conexión fuerte entre las oraciones, sino una mera indicación de adición, concomitancia, y similares, o bien establecen relaciones dentro de bloques de información, que se superponen a otros y, por tanto, tales marcas no lo son de la organización textual, sino de la organización de cada bloque.

\section{Información frente a apelación}

La última distinción es más sutil, pero no menos importante. Afecta al contenido del texto, pero sobre todo a su orientación, en cierto modo a su intencionalidad. Por un lado tenemos los textos que reúnen información y la ponen a disposición de los eventuales lectores, cuyo papel se habría de limitar, 
en principio, a tomar nota de esa información. Son los textos descriptivos, expositivos y narrativos: recogen información en torno a un tema, objeto o acontecimiento y la transmiten al lector para que este la conozca. Por otro lado, hay textos que no solo incorporan información, sino que pretenden actuar sobre la mente del destinatario para que este, en lugar de limitarse a recibir la información, la adopte como propia. Estos textos no tienen como objetivo principal transmitir información, sino convencer al destinatario de determinados puntos de vista sobre el mundo, es decir, apelan a su discernimiento para que los haga suyos (lo que llamamos apelación). Son los textos argumentativos, que, en esta distinción, se oponen a los otros tres tipos. Su carácter apelativo no es, por otra parte, un rasgo aislado, está en relación con los otros dos rasgos y los integra.

Un fenómeno que resulta esencial para conseguir la apelación en estos textos (y que, por tanto, distancia los textos argumentativos de los demás) es la abstracción. En efecto, la abstracción, que lleva a pasar de la información concreta a la formulación de ideas generales, tiene dos virtualidades: en primer lugar refuerza la apelación, la orientación hacia la conducta del lector, pues lo abstracto puede proyectarse sobre experiencias extrañas a las que lo originaron, por tanto, a las de los posibles lectores. Así, una frase como «Carlos tenía una biblioteca personal de tres mil volúmenes», de contenido concreto, es un dato y nada más, en cambio, «La biblioteca personal es un anacronismo» es una idea que puede interesar a cualquiera.

En segundo lugar, las abstracciones permiten agrupar, organizar y manejar grandes cantidades de información concreta en breve espacio, de manera que facilitan su unificación y su recuerdo. Así se puede comprobar en el siguiente ejemplo, tomado de un texto de Manuel Hidalgo (Proteger la basura) que defiende que la basura debe ser protegida por pertenecer a la intimidad de las personas:

En la noche del pasado domingo veía Los jueces de la ley (TVE-1), del vertiginoso técnico Peter Hyams. La película comienza de la siguiente manera: una pareja de policías de patrulla persigue a la carrera a un sospechoso por un vericueto de callejuelas de un suburbial Los Ángeles.

Cuando casi le dan alcance, el individuo, frente a su casa, arroja una bolsa al cubo de la basura. Un poli se precipita hacia el cubo, pero su compañero le advierte: cuidado, para registrar un cubo de basura se necesita una orden judicial. La Constitución federal protege hasta ese punto la intimidad de los ciudadanos.

La última frase («La Constitución federal protege hasta ese punto la intimidad de los ciudadanos»), en su abstracción, organiza, resume y da un sentido a los datos acumulados hasta el momento, proyectados en esa dirección por el marcador hipotáctico «hasta ese punto»). Se comprueba así la participación coordinada del tercer componente, la hipotaxis que, al subrayar las relaciones semánticas y pragmáticas entre los contenidos del texto, expresa los vínculos de unos hechos concretos con otros y de todos ellos con las ideas que los interpretan y organizan (abstracción). Al mismo tiempo, es en el encadenamiento aceptable de lo concreto con lo abstracto, es decir en el encadenamiento argumentativo, donde radica la pretensión de veracidad y la fuerza de convicción hacia el lector, la apelación. 


\section{El texto como unidad y como textura}

Del juego entre las categorías que venimos manejando (concreción/abstracción, parataxis/hipotaxis, información/apelación) derivan las dos propiedades más destacadas de los textos: su unidad y su textura. El texto como un todo constituye un mensaje único, no segmentable, esto es, se caracteriza por la unidad. El texto descriptivo, el texto expositivo y el texto narrativo se unifican en torno al objeto que tratan, la unidad les viene de fuera del texto: la descripción del jardín, la exposición sobre los mamíferos, la narración de lo que le pasó a Manolo cuando intentó arreglar la lámpara del salón. El texto argumentativo, por el contrario, configura su propia unidad en la organización de su contenido, todo él orientado a hacer válido y convincente el punto de vista que defiende; la argumentación es una estructura semántico-pragmática que asigna un lugar a los distintos componentes que se emplean para convencer. El texto argumentativo tiene una unidad más sólida, pero también más restrictiva, no cabe en él lo que no contribuya a la causa que se defiende.

Por otra parte, el texto se caracteriza por la trabazón coherente de sus partes, lo que le confiere su textura característica (y lo diferencia de las simples enumeraciones). Esto es resultado de la hipotaxis, del empleo de múltiples elementos de relación muy específicos que conectan las oraciones y le asignan una función en la trama narrativa o en el proceso argumentativo. Los textos descriptivos y expositivos, como hemos visto, carecen de hipotaxis, es decir, no establecen relaciones fuertes entre sus contenidos, meramente yuxtapuestos. Sin embargo, podemos considerar que cumplen esta propiedad por medio de lo que se puede llamar pseudohipotaxis, es decir por el encadenamiento lineal de los enunciados y el empleo de fórmulas de relación débiles, que no entrañan fuertes conexiones entre sus contenidos, sino que mencionan explícitamente la simple coexistencia, manifiesta ya por su presentación continuada en el texto.

En síntesis, la clasificación de los tipos de texto y los criterios para hacerla queda reflejada en el siguiente cuadro:

\begin{tabular}{|l|l|l|l|}
\hline & Abstracción & Hipotaxis & Apelación \\
\hline Descriptivo & No & No & No \\
\hline Expositivo & Sí & No & No \\
\hline Narrativo & No & Sí & No \\
\hline Argumentativo & Sí & Sí & Sí \\
\hline
\end{tabular}

Estamos de acuerdo con Isenberg (1987: 112-117) en que cada texto concreto debe pertenecer a un tipo y solo a uno. Pero los textos son entidades muy complejas con muchísimas posibilidades de variación dentro de su tipo (piénsese, por ejemplo, en todas las posibilidades que ofrece la técnica narrativa), pero también con algún riesgo de ambigüedad tipológica. Para tratar las confluencias aparentes y comprender la complejidad y diversidad inagotable de los textos podemos recurrir a dos explicaciones, una basada en la jerarquía y otra en la noción de texto compuesto. 
Las categorías que hemos utilizado permiten establecer una jerarquía que va de lo más simple (el texto descriptivo, pues carece de abstracción, orientación apelativa e hipotaxis) a lo más complejo (el texto argumentativo, pues posee esos tres componentes y, por defecto, los otros tres: la abstracción implica y es compatible con lo concreto, la orientación apelativa se hace sobre información, y la parataxis se produce por la mera presencia en el texto de unos contenidos junto a otros). La idea de jerarquía nos permite comprender las relaciones de unos tipos con otros, los puntos de encuentro y las diferencias entre ellos. En virtud de la jerarquía, los tipos más complejos pueden incorporar como componentes elementos de los niveles inferiores, aunque una vez integrados en el texto compuesto, pierden la condición de textos para cumplir una función dentro del conjunto; por esta razón es preferible hablar de descripciones, narraciones... como partes del texto compuesto, y no de texto descriptivo, narrativo, etc. Esto quiere decir que un texto narrativo puede contener descripciones y exposiciones (por ejemplo, de quienes participan en la acción y de los lugares en que se desarrolla), un texto expositivo puede contener descripciones y narraciones (como ejemplificación de sus abstracciones), y el texto argumentativo, descripciones, narraciones y exposiciones (como datos) 4 .

Por otro lado, de la misma manera que existen oraciones simples y oraciones compuestas, también se podría hablar de texto compuesto. Aunque utilizaremos más adelante esta idea, de momento no nos parece conveniente porque puede llevar a confusiones y porque, por muchos textos que integre un texto compuesto, en la configuración global los textos simples pierden su naturaleza de texto. Solo si los aislamos, podrían funcionar como textos. Una narración puede formar parte de un texto argumentativo (de hecho, la retórica la considera como una de las partes del discurso), pero, dentro de él, no es un texto narrativo, sino un bloque de datos con una función dentro de la estructura argumentativa, que es la que define la unidad del texto. Es por esta razón, el papel definidor de la unidad, por la que no nos parece adecuado, a estos efectos, el modelo secuencial de Adam (1999), que implica la difuminación de los tipos de textos en favor de un relativismo vinculado al concepto de dominante, según sea el tipo de secuencia que sobresalga: descriptiva, narrativa, expositiva, etc.

Finalmente, tanto la idea de jerarquía como el concepto de texto compuesto permiten entender que no existen textos mixtos, que un texto pertenece a una categoría o a otra, pero no a dos simultáneamente. Si es expositivo, no es argumentativo, ni descriptivo, ni narrativo; si es argumentativo, no es narrativo, ni expositivo; en fin, no existen textos descriptivo-narrativos o expositivo-argumentativos. Las variaciones estilísticas, la intervención de contenidos implícitos, la ambigüedad de algunos operadores sintácticos y la integración de textos simples en el texto compuesto pueden dificultar la asignación del texto a un tipo antes de una consideración de conjunto, pero el texto es, ante todo, una unidad de comunicación e interacción y solo como tal cumple su función textual, que está ligada a un tipo.

A continuación, haremos un breve esbozo de cada tipo y luego intentaremos analizar las ambigüedades o anomalías que puedan plantearse.

\footnotetext{
${ }^{4}$ El texto expositivo y el texto argumentativo ocupan una posición intermedia y equivalente en la jerarquía y, por tanto, no es infrecuente encontrar exposiciones en los textos narrativos y narraciones en los textos expositivos.
} 
Tipología textual y texto literario

\section{Los tipos de texto}

\section{1. Texto descriptivo}

Un texto descriptivo es un conjunto cerrado de enunciados unificado sobre un objeto concreto; sirve para identificarlo y diferenciarlo. La clausura del texto no es estructural, no supone la articulación completa de un proceso con partes o funciones. Un texto descriptivo queda cerrado cuando, en relación con la circunstancia comunicativa en que se inscribe, se consideran agotadas las características del objeto. La descripción, pues, no posee otro factor de unificación que la que le otorga la entidad a la que se refiere, que actúa como elemento integrador de todos los datos: objeto, lugar, persona... Al carecer de abstracción y de partes estructurales interrelacionadas (hipotaxis), su textualidad es débil, la que procede de los operadores sintácticos que, aunque se limiten a señalar relaciones de coexistencia y proximidad, crean la ilusión de un entramado; es así como las percibimos como textos, con desarrollo lineal y distribución en párrafos, frente, por ejemplo, a la distribución en columna de las listas. Pero no es anómala una descripción en forma de listado: «Carlos: ojos azules, pelo castaño, labios gruesos, cejas pobladas, pómulos sonrosados».

Se observa, en una descripción de este tipo, la unidad, el valor y la significación del conjunto. La unidad está determinada por la entidad a la que se refieren esos rasgos concretos. La significación, esa misma entidad como individuo: la descripción sirve para identificarla y reconocerla en el caso de que se nos presente. No hay significación abstracta ni incitación alguna para que la produzca el lector, solo invitación al reconocimiento de un ser concreto, de un lugar, de un objeto, que puede aparecer nombrado como en muchas definiciones descriptivas (y hasta constituir el título o parte del título de la descripción), o puede ocultarse para que la descripción sirva de estímulo para su descubrimiento, como en las adivinanzas. Describir es, entonces, presentar, caracterizar una entidad, decirnos cómo es para que podamos recrearla en la imaginación, tomar nota de sus cualidades, reconocerla e identificarla. En este sentido, la descripción es una forma típicamente informativa, no apelativa, es decir, no invita al diálogo sino a la descodificación y el reconocimiento. Los objetivos externos (para qué se utiliza esa información, por ejemplo, para localizar a un delincuente) no tienen relación ni con su estructura ni con su condición textual.

La débil textualidad de la descripción explica que pocas veces constituya un texto autónomo y, sin embargo, aparezca con frecuencia inserta en los otros tipos de textos, a veces de manera reiterada, como en los narrativos, en los que se usa para caracterizar a quienes participan en la acción y a todo tipo de entidades concretas que intervienen en su desarrollo.

\section{2. Texto narrativo}

Un texto narrativo es un conjunto cerrado de enunciados que representan acontecimientos y acciones concretas interrelacionados; forman historias en las que participan diversas personas en ámbitos y momentos definidos. Por esta razón se despliega secuencial y temporalmente dejando patentes, en el propio desarrollo narrativo, las relaciones que se dan (frecuentemente de causa y efecto) 
entre los diferentes momentos; de ahí la configuración hipotáctica que distingue a la narración de la descripción, por ejemplo y le otorga un mayor rango de textualidad.

La hipotaxis propiamente dicha implica que los acontecimientos y las acciones no interesan a la narración en su aspecto puntual, sino en su duración, en sus determinaciones y en su proyección, en sus causas y en sus secuelas. Un enunciado elemental: «La marquesa llegó a las cinco», no es todavía narración, sino simple anuncio o notificación que, a nada que se desarrolle, podrá prolongarse en narración, como ocurre en la prensa con las noticias: por un lado, tenemos la información directa, escueta, en titulares, el hecho noticioso: «Tres heridos al explotar un tanque de gasolina» y luego el relato completo de los hechos, las circunstancias en que se encontraban los heridos, las causas de la explosión, las medidas que se adoptaron a continuación, etc.

La narración, en sentido estricto, es información, transmisión de datos. Pero la información propiamente dicha supone novedad, resolución de incertidumbre, no mera reproducción de lo ya conocido o esperable. La narración, por lo tanto, se refiere a acontecimientos o acciones que son informativos; por cuanto se apartan de las expectativas, suponen una ruptura de las normas, una circunstancia anómala, imprevista, sorprendente o simplemente desconocida. El carácter hipotáctico de la narración no es sino el resultado de la necesidad de desarrollar y explicar el acontecimiento novedoso.

Como todos los textos, las narraciones constituyen mensajes con receptores reales o posibles; sin embargo, no está en la naturaleza de la narración la apelación, la actuación sobre el lector. El hecho de que la hipotaxis se refiera exclusivamente a la información concreta le resta fuerza apelativa. Narrar es referir hechos de cuya existencia, real o ficticia, el lector u oyente, por decirlo de alguna manera, toma nota, se hace conocedor. Es lo que ocurre con las noticias de sucesos, como la siguiente:

Un hombre de nacionalidad británica y su hijo de 5 años fallecieron ayer ahogados en Tossa de Mar (Gerona) después de que el padre se lanzara al agua para intentar salvar al menor y a su otro hijo, de 9 años, que habían caído al mar arrastrados por una ola. El hombre consiguió rescatar al mayor de sus hijos, pero después se hundió en el mar con su otro pequeño.

El texto cuenta cosas que sucedieron; el periódico, en su dimensión narrativa, nos informa de lo que pasa; los lectores quedamos informados simplemente. El texto no nos pide que obtengamos una conclusión o desarrollemos cierta forma de conducta. Los mensajes narrativos son, en cierto modo, objetivos, representan acontecimientos que han ocurrido en el mundo y que llegamos a conocer porque nos los cuentan (dejamos, de momento, las narraciones ficticias de la literatura, aunque mucho de lo que digamos valga para ellas). Desde luego, el narrador puede mentir o transmitir unos hechos que conoce imperfectamente, pero el mensaje sigue siendo un conjunto de acciones y acontecimientos concatenados que, si no existen indicios externos sobre su falsedad, el lector tomará como verdaderos, es decir como hechos ocurridos en el mundo. 


\section{3. Texto expositivo}

Un texto expositivo es un conjunto cerrado de enunciados unificado en torno a un tema cualquiera en sentido abstracto: los mamíferos, los gatos, los planes de pensiones, el alumbrado de la comunidad, las diferencias entre la cultura latina y la norteamericana... La clausura del texto no es estructural, no supone la articulación completa de un proceso que requiere determinadas fases o partes. El texto queda cerrado cuando se considera que ya se ha dicho todo lo necesario y pertinente en la circunstancia comunicativa en que pretende inscribirse; lo que significa que el tema, en cambio, no queda cerrado, puesto que podría desarrollarse más en otras circunstancias (no es lo mismo una lección sobre los mamíferos en un libro de enseñanza secundaria que en otro de enseñanza universitaria, o en un folleto informativo de un zoo).

El desarrollo del texto expositivo consiste en presentar la información disponible sin necesidad de ajustarse a un esquema predeterminado, aunque por razones de claridad y adecuación puede adoptar distintos patrones (comparación, cronología, subtemas, etc.) que actúan como criterios de distribución. En general, para los temas tratados de manera extensa, los textos se organizan en esquemas que los parcelan en tres grandes categorías (componentes, aspectos y relaciones), que a su vez pueden dividirse en subcategorías (por ejemplo, los componentes pueden ser partes materiales, partes orgánicas, fases si tienen un desarrollo temporal, etc.). El texto no defiende las ideas, las muestra. Los contenidos no se relacionan para progresar en una dirección, confluyen en la caracterización de un tema. El lector queda enterado de la información como conocimiento pasivo, pues no puede hacerlo suyo de forma crítica, ya que, al no elaborarse en el propio texto, tampoco se somete a la discusión.

El texto expositivo no tiene un centro, porque la información no está organizada, porque toda la información tiene el mismo valor, porque el contenido de una parte no es necesario para comprender o hacer válido y convincente el de las otras. Por ello mismo, una parte del texto puede tener valor autónomo, constituir información suficiente para funcionar por su cuenta como texto, por ejemplo, un capítulo o epígrafe sobre los aspectos sociológicos del fútbol en un texto sobre el fútbol en general. De hecho, una sola frase con sentido completo puede constituir ya un texto expositivo completo. Es lo que ocurre con los aforismos, afirmaciones generales cuya validez no se ha sometido a discusión y no cuenta con otra autoridad que la del autor. En este mismo sentido son textos expositivos los que recogen impresiones o pensamientos de quien los redacta y no tienen otro objeto que dejar constancia de ellos.

En resumen, el texto expositivo 1) presenta de manera acumulativa y no estructurada contenidos diversos sobre un tema; 2) transmite información, busca hacer saber al lector cierto conocimiento consolidado sobre un tema, sin pretender convencerlo reflexivamente, y 3) no está centrado, ni orientado hacia ninguna información específica.

El ejemplo que proponemos es un texto expositivo muy común que se limita a superponer distintas informaciones sobre su objeto, el cómic. El primer párrafo lo define, el segundo expone (describe «en abstracto») sus distintos componentes, el tercero hace su historia y el cuarto, finalmente, habla de su éxito y difusión. Podríamos alterar el orden de algunos párrafos sin necesidad de introducir 
elementos sintácticos y semánticos que restablezcan las relaciones entre ellos, porque la única relación es de cada párrafo con el tema general, pero no de los párrafos entre sí:

El cómic, también llamado historieta o tebeo, es un relato narrativo ilustrado, cuya acción se sucede en diversas viñetas. Podríamos considerar el cómic como un medio especial de comunicación de masas cuya finalidad es el entretenimiento de los lectores.

Cada historieta está constituida por una sucesión de viñetas en las que se van narrando las peripecias de unos personajes. En cada viñeta, además de breves textos que presentan los hechos y las situaciones, se distinguen dos partes claramente diferenciadas: por un lado, la parte gráfica constituida por los dibujos que representan las actuaciones de los personajes; y en segundo lugar, los bocadillos o globos que encierran los textos que a modo de diálogo salen de la boca de los personajes.

Los tebeos nacen a finales del siglo XIX. Sus antecedentes son las caricaturas de tema político o costumbrista que solían aparecer en los periódicos, ya desde el siglo XVII. Fue en 1890 cuando el diario The World, propiedad del famoso Pulitzer, comenzó a publicar una viñeta basada en un personaje que representaba la vida diaria de las gentes de Nueva York. Como el color de la viñeta se destacaba con un fondo amarillo, a este primer personaje se le conoció con el nombre de The Yelow Kid, que en inglés quiere decir «el chico amarillo». A partir de 1914, se generalizan en EE. UU. las tiras cómicas que satirizaban la forma de pensar y las costumbres de las distintas clases sociales. En torno a 1930, aparecerán los primeros libros de historietas, que contaban las aventuras de personajes como Popeye, Batman, El Príncipe Valiente, etc. Superman, que se hará el más famoso de todos, aparece en 1938, y Mafalda, uno de los más simpáticos, verá la luz hacia 1960.

Los cómics han tenido un gran éxito desde sus inicios y hoy en día los hay de todos los temas y estilos: de aventuras, policíacos, urbanos, experimentales, etc., tanto para adultos como para niños. Sus personajes y héroes forman parte de nuestra cultura y han cobrado vida en la pantalla a través de películas y dibujos animados.

\section{4. Texto argumentativo}

Un texto argumentativo es un conjunto de enunciados que se encadenan de acuerdo con normas lógicas y lingüísticas en orden a convalidar cierto punto de vista y alcanzar el asentimiento del receptor. Su desarrollo consiste en, a partir de ciertas ideas que se consideran aceptadas, aportar datos y otras ideas accesibles que, por su relación lógica con las anteriores, permitan extraer o justificar la idea o el punto de vista que se defiende. Es la vinculación lógica entre estos tres tipos de ideas (fundamentos, datos y conclusión, equiparables a las tres fases de un silogismo: premisa mayor, premisa menor, conclusión) la que vertebra el texto y le confiere su unidad característica. La misma interpenetración que hay entre estos tres componentes facilita la omisión de alguno de ellos que, en todo caso, debe poder ser restaurado fácil e inequívocamente como un componente necesario dentro de la estructura argumentativa del texto.

En otros términos, el texto argumentativo desarrolla ante el lector un proceso de conocimiento fundado en principios que presumiblemente comparten los miembros de la comunidad en la que el texto vive, el lector va siguiendo el progreso de la información, los pasos lógicos que llevan de unos contenidos a otros, hasta llegar a la conclusión que cierra y estructura el texto. Las afirmaciones del texto deben ser intuitivamente aceptables por el lector (aquellas de las que se parte), inmediatamente accesibles, fácilmente verificables o claramente derivadas en el proceso argumentativo. De esta manera, el lector participa en la elaboración del conocimiento que se va haciendo ante sus ojos y puede hacerlo suyo o rechazarlo (si ve problemas o incorrecciones) críticamente. Como dice su nombre, el 
texto argumentativo argumenta, es decir, encadena proposiciones para obtener nuevas proposiciones y así ir venciendo las resistencias del receptor y convencerlo del punto de vista que se sustenta.

De lo anterior deriva otra característica importante. El texto argumentativo tiene un punto nuclear: el punto de vista o idea a la que la argumentación nos quiere llevar y que constituye el principal factor de unificación y estructuración, la tesis o conclusión, que, sin embargo, no tiene que cerrar el texto y puede aparecer desde el comienzo como meta. Cualquier información del texto tiene que estar relacionada y orientada, directa o indirectamente, hacia esa conclusión; en otro caso, no se justificaría su presencia en él. En la lectura de un texto argumentativo sentimos que se nos quiere llevar hacia alguna idea nueva o sorprendente o desconocida o poco aceptada. Podemos asentir, o disentir, o vacilar, pero si participamos en el interés por la temática propuesta, no podemos limitarnos a tomar nota, hemos de valorar críticamente lo que recibimos tanto en su resultado como en el proceso que conduce a él.

En resumen, el texto argumentativo 1) encadena sus enunciados según los principios de la racionalidad; 2) hace partícipe al lector del proceso intelectual que desarrolla y 3) está orientado hacia una conclusión que lo unifica y estructura.

Veamos un ejemplo de texto argumentativo ${ }^{5}$ :

La biblioteca personal es un anacronismo. Ocupa demasiado lugar en casas cada vez más chicas, es oneroso formarlas, nunca realmente se las aprovecha en proporción a su costo o volumen. Un libro leído, además, ¿no está ya en nuestro espíritu, sin ocupar espacio? ¿Para qué conservarlo, entonces? ¿Y no abundan ahora acaso las bibliotecas públicas, en las que podemos encontrar no solo lo que queremos, sino más de lo que queremos? La biblioteca personal responde a circunstancias de tiempos idos: cuando se habitaba el castillo o la casa solariega, en los que por estar aislado del mundo era necesario tener el mundo a la mano, encuadernado; cuando los libros eran raros y a menudo únicos y era imperioso poseer el codiciado incunable; cuando las ciencias y las artes evolucionaban con menos prontitud y lo que contenían los libros podía conservarse vigente durante varias generaciones; cuando la familia era más estable y sedentaria y una biblioteca podía transmitirse en la misma morada y habitación y armarios sin peligro de dispersión. Estas circunstancias ya no se dan. Y sin embargo hay locos que quisieran tener todos los libros del mundo. Porque son demasiado perezosos para ir a las bibliotecas públicas; porque se cree que basta mirar el lomo de una colección para pensar que ya se la ha leído; porque uno tiene vocación de sepulturero y le gusta estar rodeado de muertos; porque nos atrae el objeto en sí, al margen de su contenido, olerlo, acariciarlo. Porque uno cree, contra toda evidencia, que el libro es una garantía de inmortalidad y formar una biblioteca es como edificar un panteón en el cual le gustaría tener reservado su nicho.

El texto empieza presentando una idea («la biblioteca personal es un anacronismo»), y luego, de manera informal, ligeramente elíptica y retórica (en las interrogaciones), propone argumentos que la sustentan («ocupa demasiado...»), otros que explican su existencia en el pasado, para negar su eficacia en el presente («estas circunstancias ya no se dan»), y otros para rechazar algunas posibles justificaciones de la tesis contraria («porque son demasiado perezosos para ir a las bibliotecas públicas; porque...»). No hay nada en el texto que no esté orientado a sustentar la idea inicial, que es, en realidad, la conclusión del razonamiento. En el texto argumentativo, los argumentos pueden ser más o menos abundantes, puede haber argumentos dudosos o incorrectos, las argumentaciones pueden complicarse, insertarse unas en otras, acumularse argumentos de distinta naturaleza, diversificarse para volver a

\footnotetext{
${ }^{5}$ Pertenece al libro de Julio Ramón Ribeyro titulado Prosas apátridas.
} 
reunirse, omitir pasos evidentes, etc. Lo auténticamente genuino del texto argumentativo es esta unidad de orientación de todos los contenidos hacia la posición sustentada, característica que, en su sencillez y brevedad, ilustra el texto que acabamos de proponer. Todo lo que se perciba al margen de esa orientación se sentirá como extraño, superfluo o incoherente, como una incorrección que, en ocasiones, podría ser una imagen literaria.

\section{Confluencias y ambigüedades tipológicas}

Una vez caracterizados los textos, nos interesa analizar algunos factores que pueden llevar a equívocos. Estos factores proceden de la posible aparición en los tipos de las categorías inferiores de componentes propios de las superiores, en concreto, la aparición de abstracciones en textos descriptivos y argumentativos. Los enunciados abstractos son constituyentes de los textos expositivos, solo cuando se encadenan en argumentaciones pueden plantear problemas para distinguir entre estos y los textos argumentativos. Dedicaremos este epígrafe a tratar estos problemas.

\section{1. Abstracciones en textos descriptivos}

Las abstracciones pueden aparecer en los textos descriptivos y narrativos si no actúan en él como tales abstracciones, es decir, cuando no son contenido directo del texto, sino, por ejemplo, propiedades del objeto descrito o de un sujeto de la acción narrada. Así, si se describe un edificio por fuera: «Tenía cuatro ventanas, dos al lado de la puerta y dos sobre estas, a unos dos metros. Entre las dos ventanas superiores se podía leer una pintada que decía: “Gobierna mejor quien gobierna menos"》». Está claro que la última sentencia no contiene una idea que el texto quiera transmitir; el texto se limita a señalar su presencia en el objeto descrito, no es la abstracción lo que se comunica, sino el hecho de su inscripción; no deriva la información previa ni la integra, sino que es un dato más que se suma a la caracterización del objeto.

Lo mismo vale para los pensamientos de un personaje de un texto narrativo, son pensamientos del personaje, no pensamientos del texto, se cuentan como vivencia concreta del personaje, no como idea que el texto desarrolle, exponga o defienda. Esta circunstancia puede crear complicaciones en los textos narrativos en los que el narrador es también un personaje y, por tanto, se puede confundir la vivencia del personaje con el juicio del narrador; aunque no es especialmente relevante para los textos no literarios, constituye uno de los múltiples factores que complican los textos y crean problemas a la hora de determinar el tipo a que pertenecen.

Los textos descriptivos y narrativos dejan de serlo en cuanto saltan de lo concreto a lo abstracto, de los datos a generalizaciones que los estructuran y actúan como conclusión de un proceso.

La abstracción estructuradora y conclusiva puede aparecer al principio, al final o, de manera más sutil, incrustada en los datos, como en el siguiente ejemplo, en el que se describe una casa, pero no con el mero fin de identificarla, sino para ponderar sus cualidades y persuadir al lector de que la elija (subrayamos precisamente los elementos de persuasión): 
Casa de turismo rural que se alquila completa para un máximo de siete personas...

La casa ha sido restaurada con esmero, respetando al máximo las características constructivas originales y conservando, allí donde ha sido posible, las vigas de madera y la piedra vista que dan calidez y autenticidad a la vivienda. Todo ello sin dejar de incorporar las comodidades que hagan más placentera y agradable la estancia, como son una cocina completamente equipada con frigorífico, horno, microondas, encimera de gas, cafetera eléctrica, batidora, tostador de pan, etc., y unos cuartos de baño y aseo decorados con buen gusto y discreto encanto. En la planta baja, una amplia entrada da acceso, a derecha e izquierda respectivamente, a la cocina y a un cuartito de aseo, y al fondo al salón con televisión y estufa de leña. [...] La planta superior consta de una pequeña habitación con cama individual, un cuarto de aseo con ducha, y una terraza-solárium desde donde se puede disfrutar de unas espléndidas vistas tanto a la montaña como a la mar [...]. La casa está dotada de todo lo necesario para una cómoda y agradable estancia: sábanas, mantas, toallas, mantelería, vajilla y cubertería en cantidad ampliamente suficiente para siete personas. Todas las habitaciones y cuartos de baño disponen de calefacción, estando asegurado el suministro de agua caliente sanitaria mediante un termo eléctrico de ciento cincuenta litros.

\section{2. Abstracciones en textos narrativos}

Aunque el texto narrativo se caracteriza por proponer información concreta sobre acciones encadenadas, son varias las circunstancias en que puede incorporar abstracciones sin perder su identidad.

En primer lugar, como en el caso de los textos descriptivos, cuando las abstracciones pierden su condición, frecuentemente por no constituir contenido que el texto quiere transmitir, sino pensamiento personal de alguno de los participantes en la acción, que es, por tanto, un hecho más. En este caso, el contenido del pensamiento no es relevante, sino el hecho de que determinado personaje lo piense.

En segundo lugar, el texto narrativo puede incorporar abstracciones del narrador con un papel semejante al que desempeñan las descripciones, como forma de caracterizar a algún personaje o ambiente, como explicación de algún aspecto de la acción. Los rasgos físicos de los personajes, de grupos, sociedades, lugares, etc. son de naturaleza concreta, pero los morales son abstracciones, no son una característica localizada en el tiempo o en el espacio, sino una elaboración conceptual que le corresponde de una manera estable. Es lo que encontramos en el párrafo subrayado por nosotros del siguiente texto de Eduardo Galeano (de El libro de los abrazos):

Tenían las manos atadas, o esposadas, y sin embargo los dedos danzaban, volaban, dibujaban palabras. Los presos estaban encapuchados; pero inclinándose alcanzaban a ver algo, alguito, por abajo. Aunque hablar estaba prohibido, ellos conversaban con las manos.

Pinio Ungerfeld me enseñó el alfabeto de los dedos, que en prisión aprendió sin profesor:

-Algunos teníamos mala letra -me dijo-. Otros eran unos artistas de la caligrafía.

La dictadura uruguaya quería que cada uno fuera nada más que uno, que cada uno fuera nadie: en cárceles y cuarteles, y en todo el país, la comunicación era delito. Algunos presos pasaron más de diez años enterrados en solitarios calabozos del tamaño de un ataúd, sin escuchar más voces que el estrépito de las rejas o los pasos de las botas por los corredores. Fernández Huidobro y Mauricio Rosencof, condenados a esa soledad, se salvaron porque pudieron hablarse, con golpecitos, a través de la pared. Así se contaban sueños y recuerdos, amores y desamores; discutían, se abrazaban, se peleaban; compartían certezas y bellezas y también compartían dudas y culpas y preguntas de esas que no tienen respuesta.

Por lo demás, lo mismo que ocurre con las descripciones, si las abstracciones aparecen para orientar o cerrar el contenido narrativo argumentativamente, el texto pasa a pertenecer a esta categoría, que es lo que ocurre con el texto de Galeano: «Cuando es verdadera, cuando nace de la necesidad de 
decir, a la voz humana no hay quien la pare. Si le niegan la boca, ella habla por las manos, o por los ojos, o por los poros, o por donde sea. Porque todos, toditos, tenemos algo que decir a los demás, alguna cosa que merece ser por los demás celebrada o perdonada».

Por otra parte, cabe considerar que, aun sin conclusiones explícitas, el contenido narrativo las sugiera o invite al lector a extraerlas. Con frecuencia, la presencia de elementos paratextuales (un título por ejemplo) invita a relacionar el contenido con ideas y a extraer conclusiones, de manera que puede ser identificado como argumentativo con componentes implícitos o, en las condiciones que analizaremos luego, como un texto literario ${ }^{6}$. Sirva de ejemplo este otro texto, también de El libro de los abrazos de Eduardo Galeano, cuyo título es La burocracia:

Sixto Martínez cumplió el servicio militar en un cuartel de Sevilla.

En medio del patio de ese cuartel, había un banquito. Junto al banquito, un soldado hacía guardia. Nadie sabía por qué se hacía la guardia del banquito. La guardia se hacía porque se hacía, noche y día, todas las noches, todos los días, y de generación en generación los oficiales transmitían la orden y los soldados obedecían. Nadie nunca dudó, nadie nunca preguntó. Si así se había hecho, por algo sería.

$\mathrm{Y}$ así siguió siendo hasta que alguien, no sé qué general o coronel, quiso conocer la orden original. Hubo que revolver a fondo los archivos. Y después de mucho hurgar, se supo. Hacía treinta y un años, dos meses y cuatro días, un oficial había mandado montar guardia junto al banquito, que estaba recién pintado, para que a nadie se le ocurriera sentarse sobre pintura fresca.

\section{3. Texto expositivo y argumentación}

En líneas generales es fácil distinguir un texto argumentativo (que desarrolla ante y con el lector un proceso intelectual y lo dirige hacia un centro, la conclusión) de un texto expositivo (que acumula ideas sobre un asunto sin necesidad de justificarlas, pues ya se consideran demostradas, y sin dirigirlas a una conclusión), pero conviene tener en cuenta algunas circunstancias que pueden llevar a confusión, especialmente en lo tocante a la abstracción.

En primer lugar, el texto expositivo y el texto argumentativo se caracterizan por la preponderancia de contenidos abstractos, que pueden aparecer de múltiples maneras: una oración («Las bibliotecas personales son un anacronismo»), una palabra (el título, por ejemplo: «La agresividad»), una serie seguida de oraciones: («La mayoría de las personas han experimentado una vez en su vida la embarazosa situación de bostezar en el momento más inoportuno y en el lugar más inadecuado, o mínimamente han realizado esfuerzos inauditos por contener un explosivo bostezo en público. De cualquier manera, bostezamos todos y casi todos los días. Sin embargo, paradójicamente, hasta la fecha no sabemos por qué sucede o cuál es su significado funcional.»). El texto expositivo puede contener argumentaciones y adquirir la apariencia de texto argumentativo. Y, a la inversa, un texto argumentativo contiene información abstracta que, fuera de las relaciones estructurales de la argumentación, es de naturaleza expositiva. Por esta razón, es importante analizar brevemente las diferencias que, en lo esencial, son diferencias en la función y el carácter de las argumentaciones en uno y otro tipo textual.

\footnotetext{
${ }^{6}$ Sobre las complejidades del texto narrativo y sus ambigüedades hemos tratado en Núñez (2010: 162-165).
} 
I. La argumentación estructura y abarca todo el texto argumentativo, pero solo es una parte del texto expositivo

En el texto argumentativo todas las argumentaciones están interrelacionadas en el proceso único en el que el texto va convalidando sus puntos de vista, no hay ningún corte que separe las argumentaciones, forman una cadena, una sola argumentación global en la que las conclusiones se utilizan inmediatamente como fundamento de nuevas argumentaciones. En el texto expositivo, las argumentaciones, si las hay, son solo una parte del contenido del texto y no forman un solo bloque. Son ideas que se muestran en su desarrollo, otras que aparecen simplemente enunciadas sin desarrollo argumentativo. No están encadenadas unas con otras y puede haber cortes textuales bruscos que las separen. En resumen, el texto argumentativo es todo él una argumentación, más simple o más compleja, es la argumentación la que estructura el texto; el texto expositivo es un mosaico de informaciones, algunas de las cuales pueden ser argumentaciones completas, pero el texto, en su conjunto, no es una argumentación.

II. El texto argumentativo desarrolla ante el lector un proceso argumentativo original, el texto expositivo cita ocasionalmente argumentaciones externas

Hay una segunda diferencia que nos parece también muy notable. El texto argumentativo construye ante el lector el proceso argumentativo, como si el autor reprodujera sus pensamientos o se sirviera de la textualidad para formalizarlos y compartirlos, la argumentación nace y se va haciendo con el texto, pues el designio de este es precisamente intentar convencer al lector de ciertas ideas. Se diría que el razonamiento se produce por primera vez en el texto y es la convicción que el razonamiento produce en el autor la que le hace presumir a este que el lector quedará también convencido.

El texto expositivo, en cambio, no hace surgir argumentaciones, el autor no despliega en el texto un razonamiento propio. Las argumentaciones del texto expositivo no son originales, son argumentaciones citadas, mostradas, en suma tomadas de otras fuentes. No se desarrollan para convencer al lector, se citan para informarle de su existencia previa en el dominio de conocimiento correspondiente.

III. El texto argumentativo se construye de primera mano siguiendo los principios de la racionalidad, el texto expositivo yuxtapone ideas de procedencia externa

Por último, es importante destacar una última diferencia que se relaciona con estas dos, pero que es más sutil y puede llevar a confusión. Mientras que el texto argumentativo se apoya en las leyes de la lógica y la racionalidad para construir conocimiento y, por tanto, consigue su objetivo de convencer y validar sus puntos de vista por el respeto de dichas leyes, las afirmaciones del texto expositivo se presentan de manera inmediata, sin un cuidado especial por las pruebas, de forma un tanto dogmática. No son ideas que el autor vaya construyendo, sino que ha tomado de distintas fuentes y las reúne en el texto con distintos objetivos relacionados con la transmisión de información, como ocurre con las 
lecciones de los libros de texto. La verdad o validez de las afirmaciones de los textos expositivos se sustentan en la autoridad de quien compone el texto y de las fuentes que maneja, la de los textos argumentativos en el buen uso de la racionalidad discursiva que el propio texto pone de manifiesto.

Veamos un ejemplo. Se trata de un texto de Eduardo Punset titulado ¿Una alimentación equilibrada mejora la salud mental?:

Los estudios científicos más recientes dan toda la razón a los partidarios de la dieta llamada «mediterránea». Resulta que los infartos de miocardio, los ictus y las muertes debidas a accidentes cardiovasculares disminuyen un $30 \%$ si se sigue esta dieta.

¿En qué consiste? Básicamente se trata de una dieta rica en aceite de oliva, nueces, garbanzos, pescado, frutas y legumbres.

Lo más sorprendente de todo es que se había previsto que la investigación durara muchos años, pero apenas iniciado el quinto año del experimento hubo que interrumpirlo porque había pruebas de sobra de lo que se buscaba. No parecía ético seguir investigando lo que, obviamente, ya resultaba evidente con las pruebas efectuadas.

He traído a colación, repetidas veces, el recuerdo que se me quedó grabado después de que en Boston (Estados Unidos) un gran nutrólogo me recordara la importancia del cuidado de la dieta para prolongar la vida. Hace diez años, la gente no se lo creía. Los científicos, en la web del New England Journal of Medicine, acaban de corroborarlo y pregonarlo a los cuatro vientos.

La dieta es, efectivamente, muy importante. ahora se empieza a comprender lo que debiera llamarse el «círculo de la vida». Los alimentos son la primera «píldora» por donde todo empieza. Esa comida es fundamental a la hora de medir su impacto en el riego sanguíneo. Le siguen luego sus efectos sobre los órganos internos, como el hígado, o los externos, como la piel. Después viene, lógicamente, la percepción que tienen los sentidos y los nervios de lo que se está comiendo. Y en función de esas percepciones se activan los mecanismos de decisión.

En realidad, la ciencia está llamando la atención sobre el hecho, a menudo olvidado, de que son los movimientos, y no tanto los pensamientos, los que cuentan. Muy a menudo tenemos tendencia a confirmar que los movimientos del resto de los animales -el olfato de los perros o la guía magnética de las aves rapaces nocturnas- son dignos de admiración. Y, sin embargo, no debe ni puede olvidarse que los humanos también prodigan movimientos casi milagrosos: los científicos llevan años intentando comprender los malabarismos de los bípedos para andar con dos piernas sin perder el equilibrio. ¿Ha intentado alguno de mis lectores repetir a solas los pasos concatenados, pisando una sola línea, de las modelos desfilando en un concurso de belleza? Los neurólogos utilizan una prueba idéntica para comprobar el estado de salud de pacientes con inicios de alzhéimer. ¿Se han fijado, si no, en el movimiento vertiginoso de los dedos de la joven pianista interpretando la música de Beethoven o de Lady Gaga? Se tiende a olvidar que la concentración y repetición de los ejercicios musicales puede llegar a transformar milagrosamente el movimiento de las manos.

En la base de un cuerpo bello, de una modelo rítmica o de una pianista prodigiosa se pueden identificar movimientos sin fin, en su origen primarios, pero que, al igual que una buena dieta, alargan la vida. La salud física es fundamental y puede depender de cosas tan asequibles como una buena dieta: no hace falta complicarse la vida hurgando soluciones en la medicina de las enfermedades en lugar de en la medicina de la salud. Simultáneamente se está descubriendo que la salud física es un requisito indispensable para la salud mental. ¿Les parecen pocas razones para intercambiar el pesimismo imperante por el optimismo esperado?

Con toda seguridad existen maneras más complicadas para ser feliz que las de empezar alargando la vida mediante una buena dieta o de curar los desvaríos mentales gracias a una mejor salud física. ¿Por qué arrinconarlas sin ton ni son?

El propio título parece plantear un problema que el texto habría de resolver argumentativamente. Se trata, sin embargo, de una interrogación retórica. El texto desarrolla el tema «la dieta mediterránea beneficia la salud»; no es el autor quien, a través de un razonamiento propio, propone la idea como tesis. Por el contrario, recoge una idea suficientemente conocida en diversos ámbitos y la expone: la presenta, la explica, la contextualiza, la amplía, también introduce algunos argumentos, pero no son propios, sino que aparecen insertos de forma impersonal («se empieza a comprender...«) o son atribuidos a científicos sin identificar («la ciencia está llamando la atención...»), o, aun pareciendo 
propios, están claramente enlazados con una de estas citas a las que cabe incorporarlos (así el argumento analógico que compara los movimientos de la pianista y la buena dieta puede verse como una derivación de la prueba que hacen «los neurólogos» para comprobar el estado de salud de los pacientes con indicios de alzhéimer). Son rasgos del texto expositivo ${ }^{7}$ que resuelven cualquier duda, por más que, en algunos casos pudiera llegar a producir respuestas más propias del texto argumentativo ${ }^{8}$.

\section{El ámbito de los textos expositivos y argumentativos}

En razón de las características que acabamos de exponer, los textos expositivos y los textos argumentativos son adecuados para ámbitos diferentes. El texto expositivo, que transmite un conocimiento ya elaborado, preferentemente no creado por el autor -que es un simple mediador-, sino obtenido de fuentes ajenas, con frecuencia anónimas o sin indicación de su procedencia, se usa con fines divulgativos, para transmitir saberes ya consolidados, puntos de vista públicos sobre un tema, impresiones tomadas por alguien sobre el terreno, etc. Tratan de satisfacer la curiosidad del lector o la necesidad de conocimientos sobre un tema, pero no de fomentar la controversia y el espíritu crítico. Son útiles en el sistema educativo para hacer llegar a los estudiantes muchos conocimientos de los que no necesitan comprender los fundamentos ni compartir los procesos que los convalidan, con frecuencia hundidos ya en zonas del saber a las que ya no interesa o conviene acceder ${ }^{9}$. Son, en general, textos expositivos las lecciones de los libros de texto, los artículos de las enciclopedias, los artículos de prensa y los libros de divulgación científica, algunos reportajes periodísticos que acumulan información o impresiones sobre un tema o la elaboran de experiencias directas sobre el terreno, ensayos de la misma naturaleza (la Crónica sentimental de España, de Manuel Vázquez Montalbán, por ejemplo). Salvo este último caso, la personalidad del autor cuenta poco, pues es un transmisor de saberes ajenos y no tiene responsabilidad sobre las ideas formuladas, sino sobre la calidad de sus fuentes y la fidelidad con que las recoge, aun en el caso de que no las nombre. Si un libro de biología contiene errores sobre el comportamiento de los peces, no culpamos al autor de no haber hecho experimentos en el mar o en el laboratorio o de no haber debatido suficientemente el problema para llegar a conclusiones más acertadas, sino de no haberse documentado en fuentes más actuales o fidedignas.

${ }^{7}$ El carácter difuso, variable y abierto de las fuentes que suele manejar el texto expositivo hace tolerable que no se citen o que se citen de manera genérica o ambigua. $\mathrm{Si}$, por el contrario, las fuentes son muy pocas, pero bien identificadas y extensas, el texto sigue siendo expositivo, pero la atribución se impone por honradez intelectual.

${ }^{8}$ El texto apareció publicado en XL Semanal, el de 31 de marzo de 2013, y, curiosamente con otro título, El círculo de la vida, en un blog (http://www.eduardpunset.es/20080/general/el-circulo-de-la-vida, última consulta 15/07/2017) que recibe comentarios; el carácter de estos, de confirmación y ampliación de la información, y no de polémica, es el que cabe esperar para los textos expositivos.

${ }^{9}$ Neil Postman basa su crítica a los libros de texto precisamente en esta característica de los textos expositivos (1999: 133): «Los libros de texto insisten sistemáticamente sobre cualquier cuestión como si no hubiera discusión posible, como si se tratara de algo fijo e inmutable. Y aún peor, si cabe, habitualmente no se menciona quién garantiza que tales hechos corresponden a tal caso, ni cómo o cuándo fueron descubiertos». Sin entrar en la polémica, sí queremos subrayar la importancia de que el lector reconozca la naturaleza de los textos que lee y pueda hacerse una idea de la fiabilidad de la información (autor del texto, medio en que se publica, referencias externas, etc.). 
Los textos argumentativos, por su parte, quieren ser creadores de conocimiento u opinión, introducen novedades en el panorama sociocultural, académico o científico y, por tanto, deben hacer frente anticipadamente a las resistencias que suele generar todo lo nuevo, para lo cual desarrollan su proceso argumentativo. Su objetivo es conseguir la adhesión del lector a sus puntos de vista, con los que el autor se compromete clara y explícitamente. Es posible la lectura pasiva, de reconocimiento de la información y sus justificaciones, como si fuera un texto expositivo, pero la condición argumentativa, que ha de ser suficientemente explícita, favorece también la lectura crítica, el examen de los argumentos por el lector y la respuesta interior o efectiva. Son textos argumentativos los tratados científicos y filosóficos, las monografías académicas, los editoriales de prensa, los artículos y tribunas de opinión, los ensayos de pensamiento creativo, textos cuyo contenido puede asumir el lector con plena conciencia de los argumentos que lo sustentan o del que debe poder discrepar cuando detecta fallos en la argumentación, en los fundamentos, en la validez de las pruebas. El lector siempre puede discrepar de un texto argumentativo o darse cuenta de su acuerdo. Un texto expositivo, en cambio, no suscita respuestas de esa naturaleza, porque no defiende posiciones, se limita a presentarlas.

\section{El texto literario en la tipología de los textos}

Finalmente queremos analizar uno de los aspectos que plantea problemas a la tipología de los textos: el estatuto de los textos literarios. Por un lado, pueden considerarse como un dominio aparte, fuera de la tipología; por otro, uno de los subtipos de los textos literarios, el narrativo, parece identificarse con uno de los tipos generales y, aunque en las manifestaciones más convencionales del relato literario parece haber una base formal clara para tal identificación, se vuelve problemática por las complejidades que ha ido adquiriendo a lo largo de la historia; al mismo tiempo, el género dramático parece no inscribirse en ninguno de los cuatro tipos y plantea la posibilidad de que exista uno nuevo: el diálogo. Por último, la literatura, tanto desde el punto de vista formal como en su mecanismo de significación, presenta rasgos específicos que tienen un encaje difícil en las bases de la tipología. Un poema, por ejemplo, puede ser un texto descriptivo y, sin embargo, no se limita a transmitirnos información concreta sobre un objeto.

En cualquier caso, puesto que la literatura se manifiesta como una forma de comunicación por medio de textos, el texto literario, independientemente de su género, debería tener un lugar dentro del cuadro tipológico. Nuestra propuesta es considerarlo como un texto argumentativo irregular. Quizá la etiqueta de «argumentativo» pueda resultar sorprendente y con alguna connotación no muy apropiada, pero esta connotación queda contrarrestada con la noción de irregularidad, mientras que el mecanismo de la argumentación resulta sumamente explicativo y apropiado, como trataremos de mostrar a continuación.

Ante todo, consideramos que la literatura, como arte, puede definirse como «expresión del sentimiento por medio de la palabra»; en cuanto expresión, el contenido que transmite no está representado, el texto no habla directamente de él; ese contenido es el sentimiento, que más que un 
significado nocional, es el efecto que resulta de lo que el texto dice directamente, lo que captamos más allá de las palabras, lo que en realidad el lenguaje usado de forma convencional no puede decir y por eso ha de quedar implícito. Por otra parte, el término «sentimiento» tiene un sentido muy amplio, es lo subjetivo, la relación del hombre con el mundo y la vida, vale tanto para una emoción puntual como para el carácter de un personaje o la cosmovisión subyacente en una relato. Si un poema expresa un sentimiento particular, una novela puede expresar una visión de la vida y de los hombres cuyas actitudes y caracteres también contiene.

El sentimiento, el contenido implícito, es el equivalente de la conclusión, tesis o propuesta del texto argumentativo, es la razón de ser y el factor unificador de todo lo demás. Lo que el texto literario muestra son los datos que, en el proceso de lectura, nos permiten captar ese sentido, o sentimiento, implícito ${ }^{10}$. Y, como decimos, esto vale tanto para un poema que expresa un sentimiento fugaz como para una novela compleja que contiene una visión del mundo, de la vida, del hombre y de sus relaciones. El carácter no formulado del mensaje es el primer elemento de la irregularidad y, creemos, el decisivo. El segundo se encuentra en la condición ficticia de los enunciados, es decir, el hecho de que los datos no se ajusten a la realidad empírica ${ }^{11}$ y el tercero a otras irregularidades de los enunciados, que pueden ser catalogadas como sintácticas y lógicas (la abundancia de metáforas, por ejemplo), a las que nos referiremos como «rasgos de estilo».

La división de la literatura en géneros no afecta a la posición de los textos literarios dentro de la tipología. Los textos concretos pueden ser muy diferentes unos de otros y por conjuntos (géneros o subgéneros); no hay más que pensar simultáneamente en un poema (La aurora de Nueva York, por ejemplo) y una novela (digamos Tiempo de silencio). Pero estas diferencias no afectan al régimen textual de todos ellos como texto argumentativo irregular: expresan un sentimiento sin nombrarlo. El sentimiento actúa como conclusión de la argumentación y el contenido explícito, ya sea un texto simple, una narración o una descripción, o compuesto, o un conjunto de documentos heterogéneos, contienen los datos o pruebas que han de conducir al sentimiento. Por tanto, dentro de la tipología textual, la literatura queda inscrita, en bloque, dentro de los textos argumentativos irregulares. Con ello no queremos desdeñar las notables diferencias entre los géneros, por ejemplo el papel destacado que en el poema tienen la sonoridad y el ritmo, frente a las variaciones de las técnicas compositivas o el mayor protagonismo de las acciones en los géneros «narrativos»; pero, en cualquier caso, se trata de distintas formas de sumergir en la superficie textual el sentido que no puede ser dicho: el sentimiento, que unas veces procede de la musicalidad de los versos y las evocaciones que produce, otra de las resonancias interiores de los hechos, otras de las formas en que se cuentan y, otras, en fin, de varios de estos factores coordinados. Por esta razón, nos vamos a interesar por las variedades de los textos

\footnotetext{
${ }^{10}$ La literatura, el arte, afirma Todorov (2007: 77-78), transmiten una verdad, no de adecuación a los hechos, sino de desvelamiento, de comprensión del sentido, por eso podemos considerar que este actúa como una auténtica conclusión, lo que, por otra parte está en correlación con la virtualidad de los textos narrativos de sugerir sin decir, de transformarse en argumentaciones implícitas que, cuando apuntan al sentimiento, funcionan literariamente.

${ }^{11}$ Como es lógico, existen ciertas condiciones para que esos datos sean eficaces literariamente; constituyen un capítulo muy interesante y complejo de la teoría literaria que no podemos abordar aquí. Véase Scheaffer (1999).
} 
literarios, pero no en esta dimensión de cómo se constituyen en tales, que consideramos homogénea, sino en sus relaciones con los tipos regulares de texto.

\title{
6. 1. 1. Texto descriptivo, texto narrativo y texto literario
}

De acuerdo con lo que acabamos de señalar, el texto descriptivo, el texto narrativo y el texto literario son tres tipos de texto diferentes. El texto descriptivo y el texto narrativo transmiten información concreta sobre entidades físicas o sobre acciones y acontecimientos, y en ello agotan su recorrido. Un texto literario, poema o relato, puede tener la apariencia de un texto descriptivo o de un texto narrativo, pero su valor literario está en la capacidad que tiene de expresar una visión subjetiva de las cosas. Por ejemplo, el poema de Machado, Amanecer de otoño:

\author{
Una larga carretera \\ entre grises peñascales, \\ $\mathrm{y}$ alguna humilde pradera \\ donde pacen negros toros. \\ Zarzas, malezas, jarales. \\ Está la tierra mojada \\ por las gotas del rocío, \\ y la alameda dorada, \\ hacia la curva del río. \\ Tras los montes de violeta \\ quebrado el primer albor. \\ a la espalda la escopeta, \\ entre sus galgos agudos, \\ caminando un cazador.
}

No se trata de que identifiquemos el paisaje, sino de que captemos los valores afectivos que contiene. Estos, como ya queda dicho, pueden hallarse no solo en el objeto descrito, sino en los ritmos y melodías del verso o en otros rasgos de estilo. Como texto, como conjunto de enunciados, es una descripción, pero no es un texto descriptivo, pues los datos que nos da están al servicio de esos valores que son el contenido genuino del mensaje poético.

Lo mismo ocurre con las narraciones; aunque formalmente las identifiquemos como textos narrativos, cualquier incitación a tomarlos como literarios desplaza la atención de los hechos a la experiencia vital que puedan contener para recrearla en la lectura. El carácter ficticio, nuestro desconocimiento personal de los protagonistas, algunas marcas estilísticas, el contexto en el que se nos presentan, etc. constituyen no solo señales de que se trata de algo más que un texto narrativo, sino dispositivos que favorecen una inmersión en los hechos y una lectura específica que descubre las motivaciones, los caracteres, el sentido de la vida que contienen. Por ejemplo, el siguiente relato, $M i$ hermano, Rafael Novoa:

Nunca le perdoné a mi hermano gemelo que me abandonara durante siete minutos en la barriga de mamá, y me dejara allí, solo, aterrorizado en la oscuridad, flotando como un astronauta en aquel líquido viscoso, y oyendo al otro lado cómo a él se lo comían a besos. Fueron los siete minutos más largos de mi vida, y los que a la postre determinarían que mi hermano fuera el primogénito y el favorito de mamá.

Desde entonces salía antes que Pablo de todos los sitios: de la habitación, de casa, del colegio, de misa, del cine... aunque ello me costara el final de la película. Un día me distraje y mi hermano salió antes 
que yo a la calle, y mientras me miraba con aquella sonrisa adorable, un coche se lo llevó por delante. Recuerdo que mi madre, al oír el golpe, salió de la casa y pasó ante mí corriendo gritando mi nombre, con los brazos extendidos hacia el cadáver de mi hermano. Yo nunca la saqué de su error.

Está claro que los hechos en sí no tienen interés para nosotros, pues sus protagonistas están muy lejos de los dominios de nuestra experiencia, pero nos interesan en la medida en que captamos, por ejemplo, la visión del clima familiar, de la carga emocional que apreciamos en las relaciones entre madres e hijos en general y que esta anécdota revela.

En suma, lo que queremos destacar aquí es que no se puede hacer una equiparación estricta entre texto descriptivo o texto narrativo en general y entre texto descriptivo o texto narrativo literario, que las descripciones y las narraciones de la literatura no se pueden poner como ejemplo de texto descriptivo o texto narrativo, ya que, independientemente de su calidad, la presentación como ficción apunta a la oferta de una intención, de un sentido suplementario que los transforma.

\section{1. 2. El texto literario como texto compuesto}

Como ya hemos señalado, la unidad del texto literario procede del sentido que expresa, no de la articulación de los enunciados, sino de la proyección que hacemos de los datos que estos transmiten a actitudes, sentimientos, sensibilidades, en los casos más notables, a una visión del mundo unitaria, pero compleja, que, de manera implícita, marca distancias o afinidades con otros puntos de vista, toma posiciones respecto a los conflictos, etc. Todo ello exige una muestra de datos de todo tipo que pueden presentarse de formas muy diferentes: una narración convencional con un único narrador que presenta los hechos manejando las posibilidades de la técnica narrativa, una superposición de relatos de distintos narradores, o simplemente la presentación de documentos heterogéneos que se influyen unos en otros para definir el perfil global del sentido. Un texto literario, entonces, puede estar compuesto de muchos textos simples, incluso de documentos fragmentarios o informales, transcripciones de manifestaciones orales, etc., que no llegan a tener la condición de textos; todos funcionan como datos que, por su inserción en el texto, tienden a la convergencia en la unificación de sentido. Los ejemplos más claros se encuentran en textos largos, novelas especialmente. Pantaleón y las visitadoras, por ejemplo, es una novela de Vargas Llosa que contiene narración convencional, partes militares, cartas, transcripción de programas de radio, etc. Datos que interactúan para transmitir una visión crítica y satírica del ejército, pero también del hombre y la sociedad sobre los que se proyecta no solo el autor (implícito) sino la propia visión militar, que queda registrada, junto con otras, en la diversidad de los documentos. La lectura se hace con la expectativa de la unidad del texto y, aunque esta se vea defraudada en la literalidad de los documentos, se renueva permanentemente en la medida en que se capta ese sentido profundo que los conecta. 


\section{1. 3. Texto literario e intertextualidad}

La integración de textos (distintos aunque solo sea por proceder de diferentes emisores) es ya un caso de lo que llamaremos intertextualidad ${ }^{12}$. La intertextualidad es la confluencia de dos o más voces en un enunciado, es una especie de cita, pero implícita, la adopción de las palabras de otro en el discurso de uno dejando patente que no es una apropiación o plagio, sino una mención para establecer una interacción entre las voces que produce efectos de sentido indirectos. Por ejemplo, en el siguiente fragmento, de la novela Cactus, de Rodrigo Muñoz Avia:

El coche que me entregaron era estupendo, sobre todo si tenemos en cuenta el precio que pagaba. Al ser automático, pedí al otro chico hispano que me lo entregó indicaciones sobre cómo se conducía. Lo hice en español, por supuesto. No podría decir exactamente en qué idioma me respondió. - Usted ahorita pise las brecas y voltee la key para startear el cano. Para manejar palanquee hasta drive, para baquear meta la reversa en la R, para parquear, la $\mathrm{P}$.

-Ya -le dije. Estaba un poco desbordado. Intenté hacer algo.

-No, tiene que braquear first, ahí, ahí, en la breka.

-Bueno, bueno, muy bien. ¿No podría quitarme esa camioneta? No quiero tragármela marcha atrás.

-¿La noca? No puedo. Tengo que pompearle la llanta, se ponchó. Le miré con perplejidad.

-Don’t worry -me dijo-. Baquee slow y no se mashea, ni modo. Pisé el freno, puse la palanca en la posición R y salí marcha atrás. Bastaba con levantar el pie del freno para que el coche se moviera. Conseguí no crashearme con la soca. Sin dejar de braquear palanqueé hasta drive, me despedí del chico y salí de allí. [Subrayado nuestro].

Las palabras subrayadas las dice el narrador, pero no son exactamente suyas, las toma del personaje con el que acaba de hablar y, al hacerlo, es como, sin decir nada, las comentara, produce un efecto, de burla quizá, que va más allá del mero contenido semántico. Este mecanismo se da, en este ejemplo, de manera ocasional y localizada, en el interior de un texto; pero la intertextualidad puede ser más amplia, estructural, es la que tenemos cuando se produce la confluencia de dos orientaciones textuales en un solo texto, como analizaremos a continuación.

En cierto modo, todo texto literario es intertextual en la medida en que la comunicación entre autor $^{13}$ y lector se realiza a través de enunciados que corresponden a seres de ficción (entre los que se incluye el narrador, cualquiera sea su nivel). El siguiente texto de Juan José Millás ilustra de manera elocuente el sentido de la intertextualidad por la diferencia de sexo entre el autor que lo firma y la persona que se expresa:

\section{Diario}

Cuando era pequeña, tuve un profesor de matemáticas al que le salían moscas del interior de las orejas. Él no se daba cuenta, o no le daba importancia, pero a mí me marcó la vida. Tengo asociadas las raíces cuadradas a las moscas. Me ha venido a la memoria aquel profesor porque esta noche he soñado que pasaba por delante de mí una mosca a la que intentaba seguir, pues en el sueño creía que no se mueven al azar, sino que van a un sitio u otro con algún propósito absurdo, del mismo modo que nosotros vamos al Ayuntamiento a resolver trámites o a la oficina a ganarnos la vida. La perdí de vista cuando se internó en el pasillo y entonces me desperté, aunque no del todo. En ese estado de duermevela, recordé también que aquellas moscas que

\footnotetext{
12 Puesto que estamos hablando de textos, el término «intertextualidad» nos parece el más apropiado para referirnos a la intersección o diálogo de textos que estudió en primer lugar Bajtin (1979) y que se conoce, según los contextos, con otros nombres: «dialogismo», «polifonía», «plurivocalidad», «plurilingüismo»

${ }^{13}$ No entramos ahora en el estatuto del emisor y los problemas de la comunicación. Concebimos al autor como autor implícito no representado en el texto, ni siquiera por el narrador, sus palabras no le pertenecen, por lo cual es como si las tomara prestadas de otro.
} 
salían de las orejas del profesor de matemáticas me ayudaron más de una vez a resolver los quebrados y las ecuaciones, aunque parezca un disparate.

$\mathrm{Al}$ poco, me levanté inquieta y fui al cuarto de baño. Mi marido se había dejado la tapadera del retrete abierta y vi, flotando en el agua, una mosca que agitaba las patas con desesperación. Daba miedo observarla y ponerte en su cabeza, pobre. Estuve a punto de tirar de la cadena, pero luego pensé que quizá esa mosca se había comunicado conmigo telepáticamente para que le salvara la vida (no sería la primera vez). Mientras dudaba, el insecto dejó de moverse y quise pensar que había fallecido para volver a la cama sin remordimientos. Finalmente, la rescaté con un trocito de papel higiénico, la abandoné en el borde la bañera y regresé al dormitorio llena de extrañas sensaciones. Hay momentos en la vida en los que una confluencia de casualidades puede hacerte creer que todo está conectado. De ser así, había actuado bien. Una mosca más o menos no importa, es cierto, a menos que se trate de tu mosca.

Pensé que quizá aquella me estaba destinada y que no rescatarla habría sido un error. Recé para que viviera y lo cierto es que por la mañana fui al cuarto de baño antes de que entrara mi marido y no la vi: se había salvado. Desde entonces me van las cosas mejor, como si una presencia bienhechora hubiera entrado en mi existencia. Se lo contaría a mi marido, pero ya sé lo que va a decir.

La firma no implica que identifiquemos al autor con la persona de Juan José Millás, pero sí nos obliga a considerar que el personaje que se expresa en el texto no se dirige a nosotros y que el autor implícito no confluye con el personaje, sino que muestra sus cavilaciones para que apreciemos su modo de ser o su sensibilidad. Ahora bien, esta circunstancia, que resulta evidente en el ejemplo, es la que presentan todos los textos ficticios, de forma clara cuando el narrador es intradiegético, pero también en los demás casos: el lector no identifica al sujeto que habla en el texto con su autor, por más que este sea una recreación que hace al interpretar los datos y relacionarlos con el contexto sociocultural, el marco de la comunicación y sus propios conocimientos. Aunque apenas se noten, hay dos textos, el citado, que ocupa todo el espacio textual, y el marco en el que se inserta que generalmente incluye el título.

Desde esta perspectiva, un texto literario podría estar constituido por una argumentación pura y simple, regular, porque la argumentación, el proceso intelectual que desarrolla y su intención persuasiva, no se dirigen al lector, son mostradas para que el lector capte en ellas de manera intuitiva determinaciones, sentimientos, caracteres y demás aspectos relacionales. El cuento de Juan Madrid $\mathrm{La}$ mirada reproduce las palabras de un personaje que, respondiendo a un policía, pretende justificar su actuación (argumentar), acaba de matar a una pareja de niños de doce años que querían robar en su tienda:

Mire usted, yo no soy una mula persona. Yo me dedico a mis cosas, la tienda, y ya ve usted, no es muy grande y mis hijos, que antes estaban aquí conmigo, pero la juventud, ya lo sabe usted. La juventud tira para otras cosas, pasan de la tienda, como ellos dicen. ¿Usted tiene hijos? Dios se los conserve.

$[\ldots]$ «El dinero, venga, el dinero», me dijo. Y la chica dijo eso de viejo de mierda. Pero fue al mirarle a los ojos. Yo he estado en la guerra, ¿sabe? Sé los ojos que tienen los que te quieren matar y ese chico me quería matar. Yo tengo licencia de armas, sí señor, aquí la tiene y aquí está la Magnum 357. ¿Qué? Pues nada, que me gusta, ¿a usted no? Es un arma preciosa, segura, ella me ha salvado la vida. Con licencia yo puedo tener lo que quiera. No se enfade, sigo.

Bueno, pues eso. ¿Por dónde iba?... ¡Ah, sí! Pues que veo que me pone en la garganta la pistola y le digo que sí, que le doy el dinero. Hay que decir eso, para disimular, para que se confíen. Igual hacíamos en la guerra.

Y ahí está... ¿Cómo? No señor, no me di cuenta que la pistola era de juguete ¿Cómo habría de saberlo? Lo único que supe es que me iba a matar y entonces abrí el cajón... Mire, de esta forma... y el revólver lo tenía ahí, tapado bajo los papeles. Le seguí mirando a los ojos y saqué el revólver. Disparé de cerca y me salpicó el delantal y la camisa. Es muy potente el Magnum, es un buen revólver. Ya lo ha visto. Le abrí un boquete en el pecho que... 
En fin, era su vida o la mía... ¿La chica?, ¡qué sabía yo! Podría tener un arma escondida entre las ropas, esos golfos lo hacen... Nada, a ella fue a la cabeza. Es más seguro, usted lo sabe, que es un defensor del orden.

Pues no, no, señor. No supe que el revólver era de juguete, ni que tenían doce años. A mí me parecieron de la edad de mi Arturo, ya se lo he dicho. Me parecieron como de veinte años. Y no jugaban. No era un juego. Le miré a los ojos y supe que querían matarme. Por eso los maté yo. A los dos, sí, señor.

Los argumentos se dirigen al policía que lo escucha. El lector se sitúa en otro nivel en el que se le ofrecen para que valore la dimensión humana de quien los sustenta. Es evidente que aquí, como en todos los textos literarios en general, abundan los mecanismos que invitan al lector a fijarse más en los aspectos subjetivos, a veces directamente subrayados, que en el razonamiento y en el valor de las pruebas, y aun si atiende a estos, el juicio del lector no cuenta en el nivel práctico, sino en la visión que pueda darle de las personas implicadas y el ámbito social en que se mueven.

\section{Final}

La caracterización del texto literario como texto argumentativo irregular permite incluirlo dentro del cuadro tipológico de acuerdo con los criterios que se aplican a los demás tipos y, al mismo tiempo, respetando su mecanismo de funcionamiento y su proyección comunicativa. Los márgenes de variación de los textos son muy amplios, pero los criterios aplicados para determinar los tipos y los tipos resultantes sirven para establecer un orden, analizar las posibles anomalías, proponer interpretaciones de los casos ambiguos y considerar la posibilidad de modificaciones y matizaciones de la tipología. La presentación de textos no ficticios como literarios y la abundancia de rasgos de estilo en textos no literarios son dos de las circunstancias que pueden plantear problemas, lo mismo que los textos publicitarios, cuya intención persuasiva los relaciona con los argumentativos, pero con rasgos diferenciales que los aproximan a los literarios. Hemos tratado aquí de las relaciones y confluencias entre los tipos, pero queda un interesante tema complementario, el de las fronteras entre ellos que, aunque solo sea por el papel que desempeñan en los procesos de comunicación los contenidos implícitos, pueden ser difusas, como hemos visto a propósito de la narración y los textos narrativos, y merecen un estudio más detenido.

\section{Referencias bibliográficas}

ADAM, Jean-Michel (1999): Linguistique textuelle. Des genres de discours aux textes. París, Natham. BAJTIN, Mijail (1979): Éstetika slovesnogo tvorchestva. Trad. esp. de Tatiana Bubnova. Estética de la creación verbal. México, Siglo XXI, $8^{\text {a }}$ ed.

BeAugrande, R. y Dressler, W. (1981): Introduction to Text Linguistics. New York, Longman [Trad. esp. de Sebastián Bonilla, Introducción a la lingüística del texto. Barcelona, Ariel, 1997]. ISENBERG, Horst (1983): «Probleme der Texttypologie», Linguistische Studien, 112, pp. 303-342. [Trad. esp. de L. Acosta: «Cuestiones fundamentales de tipología textual», en Enrique BERNÁRDEZ, comp., Lingüística del texto. Madrid, Arco, 1987, pp. 95-129]. 
KiBÉDI-VARgA, A. (1989): Discours, récit, image. Liège, Pierre Mardaga.

NúÑEZ RAMOS, Rafael (2010): El pensamiento narrativo. Aspectos cognitivos del relato. Oviedo, Ediciones de la Universidad de Oviedo.

Postman, Neil (1995): The end of education: Redefining the value of school. Postman, Neil. New York, Alfred A. Knopf [Trad. esp. de David Sempau: El fin de la educación. Una nueva definición del valor de la escuela. Barcelona, Octaedro, 1999]

SchaefFer, Jean-Marie (1999): Pourquoi la fiction. Paris, Seuil [Trad. esp. de José Luis Sánchez Silva: ¿Por qué la ficción? Madrid, Lengua de Trapo, 2002].

TOdOROv, T. (2007): La littérature en peril. París, Flammarion.

WERLICH, Egon (1976): A Text Grammar of English. Heidelberg, UTB. 